\title{
Health risk profile of prostitutes in Dublin
}

\author{
R J McDonnell MICGF MFPHMI ${ }^{1}$, P M McDonnell MPH MFFHMI ${ }^{2}$, \\ M O'Neill RGN RM'2 and F Mulcahy MD FRCPI ${ }^{3}$ \\ ${ }^{1}$ Health Information Unit, Eastern Health Board, Dr Steeven's Hospital, Dublin 8, \\ ${ }^{2}$ Women's Health Project, Royal City of Dublin Hospital, Dublin 2 and ${ }^{3}$ Department of \\ Genitourinary Medicine, St James's Hospital, Dublin 8, Ireland
}

\begin{abstract}
Summary: This study examined the health risk profile of prostitutes in Dublin. Clinical records of all 150 new prostitutes who attended a drop-in clinic for prostitutes in Dublin city during the period 1991-1997 were reviewed. Variables examined included: age, use of injectable drugs, human immunodeficiency virus (HIV) status, hepatitis B and C status, presence of sexually transmitted disease (STD), cervical cytology. Results showed the mean age of the women was 32 years. Among those tested, $2.5 \%$ were HIV positive, $5 \%$ were hepatitis B positive, $8 \%$ were hepatitis $\mathrm{C}$ positive and $25 \%$ had an STD. Almost $8 \%$ were injecting drug users (IDU) with higher prevalences of HIV, hepatitis B and C compared with non-IDU $(P<0.001)$. The clinic has been successful in providing a health-care facility for the specific health needs of this patient cohort.
\end{abstract}

\section{Keywords; Prostitution, sexually transmitted disease (STD), hepatitis B, human immunodeficiency virus (HIV), Dublin}

\section{INTRODUCTION}

Prostitution has been recognized as a high-risk activity for the spread of $\mathrm{STD}^{1,2}$ and recently $\mathrm{HIV}^{3}$. In addition, the presence of STD is an important co-factor for HIV transmission ${ }^{4}$. The fact that a proportion of prostitutes are IDUs who use prostitution as a means of supporting their drug habit ${ }^{5-8}$, increases the risk of HIV spread. In Europe, cases of HIV transmitted through injecting drug use or heterosexual contact continue to increase ${ }^{9}$, In 1991, the Eastern Health Board, which provides health services for this region of Ireland, initiated a Women's Health Project as part of its HIV prevention strategy. It is run from a community hospital in south Dublin and aimed at women working in prostitution, offering a wide range of health-care services. These include screening for STD, HIV testing and counselling, cervical cytology, hepatitis B screening and vaccination, and family planning. The Women's Health Project is a member of EUROPAP $^{10}$, a European network for HIV and STD prevention among prostitutes. This study describes the health profile of prostitutes attending in relation to risk factors for the spread of STD and HIV.

Correspondence to: Dr Robert McDonnell Health Information Unit, Eastern Health Board, Or Steeven's Hospital, Dublin 8, Ireland

\section{METHODS}

The Women's Health Project provides health-care services for prostitutes through a weekly drop-in clinic during the late evening. Prostitutes are encouraged to attend by outreach workers. A basic health screen for risk factors related to prostitution is offered to women on their first attendance. We undertook a retrospective study of the anonymized records of all new prostitutes who attended between 1991 and mid-1997. Parameters measured were as follows: age, marital status, smoking status, injecting drug use, hepatitis B and C status, proportions who undergo HIV testing, proportions who had screening and diagnosis of STD on attendance and methods of family planning. The data were analysed on Epi Info 6-04 software $^{11}$. Chi-square tests for statistical significance and relative risks were calculated. Where items of data are missing, the analysis relates to the number for which data were available.

\section{RESULTS}

A total of 150 prostitutes attended the clinic during the study period. The age of women ranged from 16-59 years. Smoking status was available for 140 women; 83\% (116/140) of whom smoked. Higher proportions of women in older age groups smoked although this did not reach statistical significance. The marital status was available for 137 women, of these, $26 \%$ $(36 / 137)$ were married, $50 \%(69 / 137)$ were single and $23 \%$ $(32 / 137)$ were separated or divorced.

This article is a reproduction of that published in: International Journal of STD \& AIDS, 9, 1998, pp.485-488. Pagination may not match that of the original. 
Table 1 shows the proportions of women who were smokers or who were separated/divorced in each age group.

Eight per cent (12/150) of the women reported that they were current IDUs. Their mean age was 25.8 years compared with 32.2 years among non-IDU prostitutes $(P<0.05)$. They were less likely than non-IDU women to undergo testing for HIV, hepatitis $\mathrm{B}$ or hepatitis $\mathrm{C}(P<0.01)$ and had higher seropositivity rates for these infections than prostitutes who were not IDUs (Table 2).

Seventy-nine per cent $(119 / 150)$ of the prostitutes were tested for HIV, of whom $2.5 \%$ (3/119) were positive. Eightythree per cent (124/150) of women were tested for all hepatitis B markers of whom $4.8 \%(6 / 124)$ showed evidence of current or previous infection. The 118 women who tested negative were offered hepatitis B vaccinations, of whom $25 \%(30 / 118)$ have completed the course of three injections and $20 \%$ (23/118) have had 2 injections. Sixty-six per cent (99/150) of the prostitutes were tested for antibody to hepatitis $\mathrm{C}$ by enzyme immunoassay test; $8.1 \%(8 / 99)$ were positive.

Almost all the women reported using condoms on all occasions with clients as a means of protection against STD, but the majority also reported burst condoms on at least one or more occasions. Data on contraceptive methods used with their non-client partner were available for 128 women; $19.5 \%$ $(25 / 128)$ used condoms as their method of contraception (Figure 1). The most frequent method used was the oral contraceptive pill. Almost $16 \%$ (20/128) used no contraception.

Data on cervical cytology were available for $65 \%$ (97/150) of women. Of these, $45 \%$ (44/97) had a normal smear result, 35\% (34/97) had an inflammatory smear and 19\% $(18 / 97)$ had evidence of dysplasia, which was moderate or severe in 8

Table 1. Age of women, smoking and marital separation or divorce

\begin{tabular}{llrlr}
\hline Age group & \multicolumn{2}{l}{ No. smokers } & \multicolumn{2}{l}{ No. separated/divorced } \\
& $n=140(\%)$ & \multicolumn{3}{l}{$n=137(\%)$} \\
\hline Under 20 years & $7 / 10$ & $(70)$ & $0 / 10$ & $(0)$ \\
20-29 years & $41 / 53$ & $(77)$ & $3 / 51$ & $(6)$ \\
30-39 years & $40 / 45$ & $(89)$ & $15 / 45$ & $(33)$ \\
40-49 years & $22 / 26$ & $(85)$ & $11 / 24$ & $(46)$ \\
Over 50 years & $6 / 6$ & $(100)$ & $3 / 7$ & $(43)$ \\
\hline
\end{tabular}

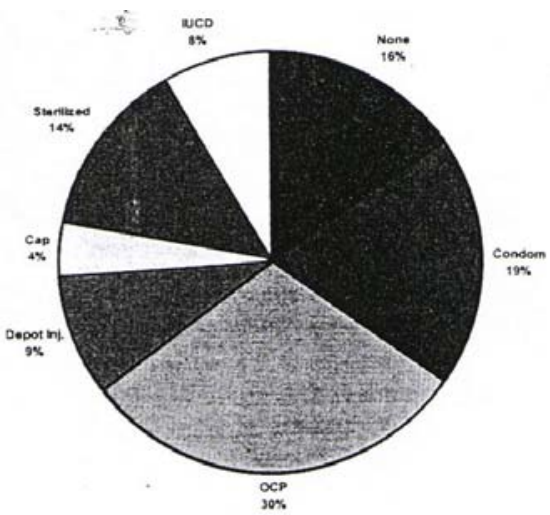

Figure 1. Methods of contraception with partner. IUCD: intrauterine contraceptive device, OCP=oral contraceptive pill

women. Screening for STD was available for 3 of the 6 years of the study. Of 94 women offered screening, 85 availed of the service representing $57 \%(85 / 150)$ of all the prostitutes; $25 \%$ $(21 / 85)$ had documented evidence of infection. Of these, the most frequently encountered infections were genital warts (8/21), Chlamydia trachomatis (4/21) and Trichomonas vaginalis $(3 / 21)$. Women with STD were significantly more likely to have an inflammatory or dysplastic smear than those with a normal STD screening result $(P<0.05)$ and the relationship was strongest for genital warts $(P<0.05)$.

\section{DISCUSSION}

This is the largest study of prostitutes in Ireland to date. Although we do not know how representative the women are of all prostitutes working in Dublin, it nevertheless represents a sizeable sample of the estimated 600 prostitutes in the city ${ }^{10}$. The clinic is located in the south side of the city and may not be readily accessible to some prostitutes working elsewhere. The women in this study are mostly 'street workers' and generally ensure anonymity by giving their working name rather than their real names, even though confidentiality is assured. They are encouraged to return to the

Table 2.Risk profile of prostitutes for HIV, hepatitis B and C

\begin{tabular}{lllllll}
\hline & \multicolumn{2}{l}{ Non-IDU prostitutes } & \multicolumn{2}{l}{ IDU prostitutes } & Relative risk (CI) & $P$ value \\
\hline HIV & $1 / 113$ & $(0.9 \%)$ & $2 / 6$ & $(33.3 \%)$ & $37.7(4.0-359.4)$ & $P<0.001$ \\
Hepatitis B & $3 / 119$ & $(2.5 \%)$ & $3 / 5$ & $(60.0 \%)$ & $15.25(3.64-63.82)$ & $P<0.001$ \\
Hepatitis C & $3 / 93$ & $(3.2 \%)$ & $5 / 6$ & $(83.3 \%)$ & $26.67(8,28-85.91)$ & $P<0.001$ \\
\hline
\end{tabular}

IDU=injecting drug user

$\mathrm{CI}=$ confidence interval 
clinic on a 6-monthly basis, but some attend for only one visit, missing out on tests as well as other services such as hepatitis $\mathrm{B}$ vaccination; this has given rise to some of the missing data in this study. A small minority refused to have specific tests or may not have provided information on different aspects of their health for various reasons.

The vast majority were smokers, where older women were more likely to smoke; smoking has also been found to be a serious problem among both brothel and street prostitutes elsewhere ${ }^{12}$. Although half of the prostitutes were married at some stage, the proportion of women who were separated or divorced is much higher than in the general population. Data from the 1991 census $^{13}$ showed that approximately 5\% of married women were separated or divorced, compared with well over one-third of the prostitutes in this study.

The proportion of prostitutes who are IDUs varies between countries and between cities within the same countries $^{10}$. In our study, the proportion who were IDUs is similar to that found by Ward et al. in their study of prostitutes in London ${ }^{1}$, but much lower than that of a drop-in centre for prostitutes in Glasgow ${ }^{14}$ where more than three-quarters were IDUs. Prostitutes who are IDUs appear to be a different population from those who are non-IDUs; many IDU prostitutes work primarily to fund their habit and would give up prostitution if they were not using drugs ${ }^{8}$. The women who were IDUs in our study were younger and had the least favourable health risk profile among all the prostitutes. Some were reluctant or unable to undergo testing at the clinic, others may have been tested elsewhere. It is more difficult to attract women who are IDUs to the clinic even though they may be in greater need of the services provided. It is therefore likely that the proportion of IDU prostitutes attending our clinic are an underestimate of the overall proportion working in prostitution in Dublin.

The prevalence of HIV infection among all prostitutes who were tested is lower than the $5 \%$ prevalence reported from a multicentre study of prostitutes in European countries $^{15}$, and slightly higher than the $0.9 \%$ among London prostitutes reported by Ward et al. ${ }^{1}$ In our study, the use of injectable drugs by the prostitute was the main determinant of HIV, hepatitis B and C status. However, there is evidence that the seroprevalence of HIV and hepatitis B among IDUs is decreasing in recent years due to safer needle sharing practices. A sample of male and female IDUs attending the National Drug Treatment Centre in Dublin during the same time period as this study showed much lower prevalences of HIV, hepatitis B and hepatitis C at 1.4\%, 1.4\% and $62.9 \%$ respectively (personal communication). Thus, as only half of the 12 IDU prostitutes in our study were tested for these infections, the proportions of IDU prostitutes who are seropositive must be interpreted with caution as numbers are small and the declining seropreva- lence among IDUs generally may not yet be reflected among IDU prostitutes.

STD screening at the clinic was not undertaken during 3 of the 6 years of the study while the service and facilities were being reviewed and reorganized. Notwithstanding this, a quarter of the women screened were positive for STD, which is broadly similar to prostitutes elsewhere ${ }^{16-18}$. The majority of prostitutes in our study reported episodes of condom failure with clients. A higher than expected prevalence of STD could be explained by inaccurate reporting of condom use ${ }^{18}$ or a risk of STD associated with prostitutes' noncommercial sexual relationships ${ }^{1}$.

In conclusion, this study has found that targeting specific health services for this group of women has been of value in the Irish context. It allows monitoring of health risk behaviours and provides a means for improving the health of the women themselves and consequently the health of the public.

\section{References}

1 Ward H, Day S, Mezzone J, et al. Prostitution and risk of HIV: female prostitutes in London. BMJ 1993;307(6900): 356-8

2 Woolley P, Bowman C, Kinghorn G. Prostitution in Sheffield: differences between prostitutes. Genitourin Med 1988;64:391-3

3 Siraprapasiri T, Thanprasertsuk S, Rodklay A, Srivanichakorn S, Sawanpanyalert P, Temtanarak J. Risk factors for HIV among prostitutes in Chiangmai, Thailand. AIDS 1991;5:579-82

4 Padian N, Shiboski S, Glass S, Vittinghoff E, Heterosexual transmission of human immunodeficiency virus (HIV) in Northern California: results from a ten year study. Am J Epidemiol 1997; 146(4): 350-7

5 Patel R, Radcliffe, Rogstad K. Feedback on the Tenth International Congress on AIDS/International Conference on STD. Int J STD AIDS 1994;5:450-5

6 Rhodes T, Stimson G, Quirk A. Sex, drugs, intervention, and research: from the individual to the social. Subst Use Misuse 1996:31(3):375-407

7 Breteville-Jensen A, Sutton M. The income generating behaviour of injecting drug users in Oslo. Addiction 1996;91 (1): 63-79

8 Gossop M, Powis B, Griffiths P, Strang J. Sexual behaviour and its relationship to drug taking among prostitutes in south London. Addiction 1994;89(8):961-70

9 Coates T, Aggleton P, Gutzwiller F, et al. HIV prevention in developed countries. Lancet 1996;348:1143-8

10 EUROPAP Co-ordinating Centre. EUROPAP 1994 Final Report-European Intervention Projects AIDS Prevention for Prostitutes. Ghent, 1995

11 Dean A, Dean J, Coulombier D, et al. Epi Info, Version 6. A word processing, database, and statistics program for epidemiology on microcomputer. Centers for Disease Control and Prevention, Atlanta, 1994

12 Perkins R, Lovjoy F. Healthy and unhealthy lifestyles of female brothel workers and call girls (private sex workers) in Sydney. Aust $N Z$ L Public Health 1996;20(5):512-16

13 Central Statistics Office- Census 91-Age and Marital Status 1994. Dublin: Stationery Office

This article is a reproduction of that published in: International Journal of STD \& AIDS, 9, 1998, pp.485-488. Pagination may not match that of the original. 
14 Green S, Goldberg D, Christie $\mathrm{P}$ et al. Female streetworkers-prostitutes in Glasgow: a descriptive study of their lifestyle. AIDS Care 1993;5(3) :321-35

15 European Working Group on HIV infection in female prostitutes. HIV infection in European female sex workers: epidemiological link with the use of petrolium based lubricant. AIDS 1993;7(3):401-8

16 Gossop M, Powis B, Griffiths P, Strang J. Female prostitutes in south London: use of heroin, cocaine and alcohol, and their relationship to health risk behaviours. AIDS Care 1995;7(3): 253-60
17 Mesquita P, Granato C, Castelo A. Risk factors associated with hepatitis $\mathrm{C}$ virus (HCV) infection among prostitutes and their clients in the city of Santos, Sao Paulo State, Brazil. J Med Virol 1997;51(4):338-43

18 Tchoudomirova K, Domeika M, Mardh P. Demographic data on prostitutes from Bulgaria - a recruitment country for international (migratory) prostitutes, Int J STD AIDS 1997;8(3): 187-91

(Accepted 25 February 1998) 